\title{
Is supernatural belief unreliably formed?
}

\author{
Hans Van Eyghen ${ }^{1}$ iD
}

Received: 28 September 2017/ Accepted: 25 April 2018/Published online: 5 May 2018

(C) The Author(s) 2018

\begin{abstract}
I criticize 5 arguments for the conclusion that religious belief is unreliably formed and hence epistemically tainted. The arguments draw on scientific evidence from Cognitive Science of Religion. They differ considerably as to why the evidence points to unreliability. Two arguments conclude to unreliability because religious belief is shaped by evolutionary pressures; another argument states that the mechanism responsible for religious belief produces many false godbeliefs; a similar argument claims that the mechanism produces incompatible godbeliefs; and a final argument states that the mechanism is offtrack. I argue that the arguments fail to make the case for unreliability or that the unreliability can be overcome.
\end{abstract}

Keywords Cognitive science of religion · Religious epistemology · Debunking arguments · Reliabilism - Rationality of religious belief

A number of authors have claimed that recent scientific evidence shows, or at least strongly suggests, that supernatural belief is unreliably formed and hence its epistemic status is tainted. I will call their arguments 'unreliability arguments'. Another group of authors argues that scientific evidence shows or suggests no such thing. In this paper, I distinguish four unreliability arguments in the literature. I argue that they either fail to make a case for unreliability or that it need not affect the status of supernatural beliefs.

Hans Van Eyghen

hansvaneyghen@gmail.com

1 Department of Philosophy, VU Amsterdam, De Boelelaan 1105, $1081 \mathrm{HV}$ Amsterdam, The Netherlands 


\section{Unreliability arguments}

Unreliability arguments in the domain of religious belief take the following generic form:

(1) Scientific evidence shows that the mechanisms that produce supernatural beliefs are unreliable.

(2) Beliefs that are produced by unreliable mechanisms suffer from an epistemic deficiency.

(3) Therefore, supernatural beliefs suffer from a serious epistemic deficiency.

All unreliability arguments I discuss in the next sections follow this general schema. The main differences lie in how they argue for premise (1). ${ }^{1}$ Some conclude to unreliability because the scientific evidence shows that the mechanisms for supernatural belief were shaped by natural selection. Others argue that the scientific evidence shows that the mechanisms produce many false god-beliefs. A related argument states that the mechanisms produce mutually incompatible beliefs. A final argument concludes to unreliability because there are independent, internal reasons to believe the mechanisms are unreliable. Before discussing these arguments in more detail, I define some key terms.

\section{Supernatural belief}

To understand unreliability arguments, some terms and phrases need clarification. The first term that needs to be made clear is 'supernatural belief'. Some who discuss its alleged unreliability use the term 'religious belief'. ${ }^{2}$ Many authors who defend or attack unreliability arguments, use the terms 'belief in God' or 'belief in gods'. Kelly Clark for example explicitly discusses belief in God, both in his own work and in a paper with Justin Barrett. ${ }^{3}$ Liz Goodnick's argument is aimed at belief in God. ${ }^{4}$ Joshua Thurow uses the term belief in "a god of some kind". 5 Justin Barrett uses the term "belief in gods". 6 Those who use the term 'belief in God' appear to have belief in the Christian God in mind. Thurow and Barrett are more inclusive and use the term 'belief in god' or 'belief in gods' as including belief outside of Christian communities as well. Some use the term 'theism' or 'theistic belief(s)'. In a paper with Dani Rabinowitz, Kelly Clark uses 'theistic belief'.? Matthew Braddock uses the term 'theistic beliefs' and 'god-beliefs'

\footnotetext{
${ }^{1}$ I will not contest premise (2). Some criticisms against reliabilism in general will also count against this arguments (e.g.Conee and Feldman 1998). I lack the space to go into their arguments in this paper.

2 Examples are Wilkins and Griffiths (2013), Murray (2008), Jones (2016), Leech and Visala (2011) and Nola (2013).

${ }^{3}$ Clark (2010), Clark and Barrett (2010).

${ }^{4}$ Goodnick (2016).

5 Thurow (2013: 77).

${ }^{6}$ Barrett (2007: 57).

${ }^{7}$ Clark and Rabinowitz (2011).
} 
interchangeably. ${ }^{8}$ Jonathan Jong and Aku Visala refer to 'theism'. 9 Theism is often defined as the thesis that there exists at least one god. Therefore 'theistic belief' includes both belief in one god and belief in multiple gods. One author who stands out is Peter van Inwagen. He uses 'supernaturalistic belief' ${ }^{10}$ This term is the most inclusive. It can include belief in more abstract supernatural forces like the Chinese concept of Dao or Indian concept of Brahman.

In this paper I will use the term 'supernatural belief'. As the previous paragraph shows, the arguments I discuss are not aimed at other religious beliefs. My main reason is that it allows inclusion of non-Abrahamic beliefs and does not suffer from the vagueness and generality associated with 'religious belief'. The term is also wider than 'theism' or 'theistic belief' and includes beliefs about the nature of supernatural beings. I take 'supernatural belief' to mean:

beliefs about the existence or nature of supernatural beings

I believe using the term 'supernatural belief' is in line with the intentions of the authors I discuss below. Although some use broader terms, they seem to have supernatural belief in mind. The arguments of those that use narrower terms can also be applied to supernatural beliefs.

\section{The scientific evidence}

The scientific evidence unreliability arguments refer to is drawn from a discipline known as Cognitive Science of Religion (CSR). The discipline hosts a large number of theories. The theories debunkers refer to are the 'Hyperactive Agency Detection Device' (HADD), the 'Existential Theory of the Mind' (EToM), the 'Cognitive Optimum' (CO), 'Broad Supernatural Punishment Theory' (BSPT) and the 'Big Gods Theory' (BGT). ${ }^{11}$

According to HADD, people acquire their supernatural beliefs because the mechanism by means of which they detect agents is prone to hyperactivity; it detects agents where none are present. For this reason, people are inclined to interpret the rustling of leaves as caused by an animal or fellow human being rather than caused by the wind. Justin Barrett suggests this was beneficial for our ancestors because it is safer to detect too many predators than too few. Similarly, upon hearing a noise or seeing movement where no agent is to be seen, the human mind might jump to the conclusion that an invisible agent caused it. ${ }^{12}$

EToM is defended by Jesse Bering. He proposes that supernatural beliefs result from overactivation of the Theory of Mind (ToM). He argues that people are prone to interpret meaningful events as meaningful communications from a divine mind. The ToM is usually used to form beliefs about other people's mental states. It

\footnotetext{
8 Braddock (2016).

9 Jong and Visala (2014).

10 Van Inwagen (2009: 129).

11 All theories are not without their critics (see: Oviedo 2018; Szocik 2018). I will not discuss criticisms of any of these theories in detail and proceed as if they are true.

12 Barrett (2004).
} 
interprets outward evidence as cues about what a person is thinking or feeling. Sometimes it takes symbolic gestures as evidence. For example, a gentle tug on a shoulder can be interpreted as showing that someone feels compassion. According to Bering, the ToM will also interpret meaningful events as evidence for mental states. Events like a beautiful sunset or the birth of a child have meaning and meaning is intuitively connected with intentionality. Since normal people lack the power to bring these events about, the meaningful events are interpreted as symbolic gestures that indicate mental states of a greater mind, or an ultimate meaninggiver. $^{13}$

Arguably the most influential CSR-theory is Pascal Boyer's 'Cognitive Optimum'. He argues that minimally counterintuitive concept have the best chances of being remembered and being transmitted. In his view, people have intuitive ontological categories like 'Plant', 'Animal' or 'Person'. These categories allow for predictions. For example, categorizing something under 'Plant' allows the inference that the thing will not be able to move and will grow under the right conditions. Minimally counterintuitive concepts violate some of the expectations that come with their intuitive ontological category. For example, a ghost is usually categorized under 'Person' but violates the expectation that persons cannot move through walls. At the same time the majority of expectations is retained and a ghost is expected to perceive things in the same way persons do and to interact with others like persons do. Minimally counterintuitive concepts differ from intuitive (concepts that violate no expectations) and maximally counterintuitive concepts (concepts that violate many expectations). Intuitive concepts, like 'John Doe', are not memorable because they are ordinary and maximally intuitive concepts, like a man who is $30 \mathrm{~m}$ long, has 11,5 arms and only appears every second Tuesday of the month, require too much cognitive effort to remember. Most supernatural concepts are minimally counterintuitive and thus easily transmitted and remembered. ${ }^{14}$

Defenders of the Broad Supernatural Punishment Theory ${ }^{15}$ start off from the observation that humans rely on cooperation to a far greater extent than any other animal. In consequence, social behavior is necessary for human survival and humans need to be able to rely on others. However, in every group there is the possibility of free-riders; individuals who trick others into believing they will cooperate but in the end do not. To know if others are trustworthy, they need access to strategic information. Pascal Boyer defines strategic information as "the subset of all the information(...) that activates the mental systems that regulate social interaction" (Boyer 2002: 173): in other words, the information on which humans base their strategies for social interaction (intentions, motives,...). Unfortunately, people do not have access to other people's mental lives. Having the idea that a supernatural being, with full access to every thought, is watching would increase the incentive to follow the social norms of one's group and thereby increase the odds that a person will be trustworthy. The all-seeing being is also believed to be especially interested in people's moral behavior, and to offer prospects of reward or

\footnotetext{
13 Bering (2002).

14 Boyer (2002).

15 See for example Johnson (2015), Bering and Johnson (2005).
} 
punishment in accordance with moral behavior, which creates an even greater incentive to follow social norms.

BGT closely resembles BSPT but puts the adaptive use of all-seeing gods in cultural evolution instead of biological evolution. BGT claims that the use of believing in gods to make sure people are collaborating only became apparent when people started living in larger societies. Around that time (8th to 3th century B.C.), groups with belief in all-seeing gods outcompeted other groups and became dominant.

Though the authors I discuss below build their arguments around one or more theories, some authors claim their argument also works if another CSR-theory is plugged in. Nola sees his unreliability argument as a general schema for a number of theories. ${ }^{16}$ Wilkins and Griffiths ambitiously claim that all contemporary evolutionary explanations of theistic belief hypothesize that they are unreliably formed. ${ }^{17}$ Braddock also suggests his argument does not depend on a specific theory when he writes: "Mechanisms [responsible for theistic belief] include the hyperactive agency detection device (HADD), the theory of mind faculty, and mechanisms underlying various content biases (e.g. for minimally counterintuitive concepts, teleological thinking, mind/body dualism)."18

Authors use different terms to refer to the cognitive mechanisms laid bare by CSR. Some use the term 'mechanism' or 'belief-forming mechanism'. Other use 'faculty' or 'belief-forming process'. All terms are interchangeable. I will use the term 'mechanism' or 'CSR-mechanism'.

\section{Epistemic deficiencies}

The epistemic deficiencies mentioned in the second premise can be manifold. Braddock draws the conclusion that theistic beliefs are rendered unjustified by scientific theories. ${ }^{19}$ Nola concludes that theistic beliefs are debunked. ${ }^{20}$ Wilkins and Griffiths write that debunking arguments should undermine our confidence in theistic beliefs. ${ }^{21}$ Goodnick concludes that theistic beliefs are unwarranted ${ }^{22}$ Clark responds to "arguments that claim to demonstrate that evolutionary psychology undermines rational belief in God". ${ }^{23}$ He thereby suggests that unreliability arguments undermine the rationality of theistic belief.

Being unjustified, being debunked, being undermined and being irrational are not the same. Nonetheless, these qualifications all give a negative verdict on the

\footnotetext{
${ }^{16}$ He writes: "This suggests a general schema for a number of naturalistic hypotheses about how the operation of our minds can be claimed to cause religious belief." (Nola 2013: 163).

17 They write: "[N]one of the contemporary evolutionary explanations of religious belief hypothesizes that those beliefs are produced by a mechanism that tracks truth." (Wilkins and Griffiths 2013: 141).

18 Braddock (2016: 269 emphasis added).

19 Braddock (2016).

20 Nola (2013).

21 Wilkins and Griffiths (2013).

22 Goodnick (2016).

23 Clark (2010: 514 emphasis added).
} 
epistemic quality of a belief. All the unreliability arguments conclude to some serious epistemic deficiency of supernatural belief. In the remainder of the paper I will not opt for one of these negative qualifications and leave it at 'serious epistemic deficiencies'.

In what follows, I discuss five unreliability arguments. In section two I discuss two evolutionary unreliability arguments; in section three, I discuss an argument that claims CSR-mechanisms produce many false god-beliefs; in section four I discuss a similar argument that claims the mechanisms produce incompatible beliefs. Finally in section five I discuss an argument that points out that CSRmechanisms are off-track.

\section{Evolutionary unreliability arguments}

\section{Goodnick's evolutionary debunking argument}

The most popular unreliability arguments against supernatural belief are evolutionary unreliability arguments. Arguments of this kind are defended by Liz Goodnick as well as by John Wilkins and Paul Griffiths. The two arguments differ considerably from each other. I discuss Goodnick's argument first because hers is the most straightforward. She writes:

$[B]$ eliefs caused by HADD + ToM + EToM + MCI [The Cognitive Optimum] are caused by faculties that were selected for by natural selection. Faculties that were selected for by natural selection are, first and foremost, selected for their facilitation in survival and reproduction - not because they attempt to represent the truth. Because religious beliefs are not caused by a belief-forming mechanism aimed at the production of true beliefs, they should not be trusted. The beliefs they produce are unwarranted for the same reason beliefs based on wish-fulfillment are unwarranted: even if they happen to be true, it will be because the believer "got lucky" in this case. (Goodnick 2016: 26)

Goodnick's argument can be summarized as follows:

(1) The scientific evidence shows that the mechanisms that produce supernatural beliefs were selected by natural selection.

(2) Mechanisms selected by natural selection are primarily aimed at survival and not at truth.

(3) Mechanisms that are not primarily aimed at truth are unreliable.

(4) Therefore, the scientific evidence shows that the mechanisms for supernatural beliefs are unreliable.

Goodnick rightly notes that (many) CSR-theories state that the mechanisms at the root of supernatural belief were selected by natural selection. ${ }^{24}$ Combined with the

\footnotetext{
${ }^{24}$ Whether the mechanisms are adaptations in themselves or by-products does not matter here. Byproducts were also selected for by natural selection along with the adaptations they hinge upon.
} 
premise that natural selection selects primarily for survival success and not for truth, she concludes that the mechanisms responsible for supernatural belief are unreliable and its resulting beliefs unwarranted.

To my knowledge, no author has responded directly to Goodnick's argument. Some have offered responses to similar arguments they constructed themselves. They deny that an evolved mechanism cannot be primarily aimed at truth. Justin Barrett and Ian Church argue that a cosmos-designing god could have appropriately tuned the mechanism(s) responsible for religious belief to make himself known. ${ }^{25}$ Kelly Clark and Justin Barrett claim that God could have implanted the mechanism responsible for religious belief. ${ }^{26}$ Alvin Plantinga makes the same argument. ${ }^{27}$ They claim that, because it was guided by God, evolution can select for mechanisms that are aimed at truth. It can, because, for the responders, evolution is not a blind process aimed solely or even primarily at survival; in their view evolution is to some extent guided by a god. Clearly their responses rely on a form of theistic evolution. Theistic evolution does not deny that evolutionary processes are usually aimed at survival. It adds that a god sometimes directs or tweaks the evolutionary processes or that a god laid out the path of evolution in a particular direction. The responders suggest that a god directed evolutionary processes to form the mechanism for supernatural belief. In doing so, these authors deny the second premise.

Another response is that unambiguously claiming that belief-forming mechanisms which were selected by natural selection are not aimed at truth is problematic. Many (if not most) of our belief-forming mechanisms were selected by natural selection. These include our sense perception and common sense and even our ability to do science. Goodnick's argument could thus do a lot more damage than she intends: it leads to what might be called 'evolutionary skepticism'. Evolutionary skepticism also casts doubt on Goodnick's own premises since they were likely formed by common sense. Another evolutionary debunking argument proposed by John Wilkins and Paul Griffiths attempts to evade this problem. Let us discuss their view now.

\section{Wilkins and Griffiths' evolutionary unreliability argument}

Wilkins and Griffith proposed a different evolutionary unreliability argument. They argue for the following:

(5) Mechanisms that were selected by natural selection can either be constrained by reality or not.

(6) If they are constrained by reality they are reliable.

(7) If they are not constrained by reality they are unreliable.

(8) The scientific evidence does not show that the mechanisms for supernatural beliefs are constrained by reality.

\footnotetext{
25 Barrett and Church (2013).

26 Clark and Barrett (2010).

27 Plantinga (2011: Chapter 5).
} 
(9) Therefore, the scientific evidence shows that the mechanisms for supernatural beliefs are unreliable.

Wilkins and Griffiths do not claim that natural selection taints all belief-forming faculties. They accept that natural selection does not primarily select for truth but add that this does not force the conclusion to evolutionary skepticism. They write: "To defeat evolutionary scepticism, true belief must be linked to evolutionary success in such a way that selection will favour organisms which have true beliefs." 28 They thus start with a suspicion of skepticism of any evolved beliefforming process. Unlike Goodnick, they leave room for a possibility of overcoming the skepticism and argue that this does not happen for the mechanisms responsible for supernatural belief.

They go on to argue that in the case of many common sense beliefs, true belief (or rather having true beliefs) is linked to evolutionary success. Wilkins and Griffith call the link a 'Milvian Bridge'. ${ }^{29}$ In their view, a Milvian Bridge is:

Milvian Bridge: $\mathrm{X}$ facts are related to the evolutionary success of $\mathrm{X}$ beliefs in such a way that it is reasonable to accept and act on $\mathrm{X}$ beliefs produced by our evolved cognitive faculties. ${ }^{30}$

Applied to common sense, they argue that common sense facts can be related to the evolutionary success of common sense beliefs in such a way that it is reasonable to accept and act on common sense beliefs. They suggest that if most common sense beliefs were false, survival would be difficult, if not impossible. They write: "If an animal acts as if the world is a certain way when the world is that way, those actions will be successful. If it acts as if the world is a certain way and it is not, then those actions will be frustrated by the way the world is, and thus constitute a waste of precious resources." 31 Having true common sense beliefs is thus evolutionarily beneficial whereas having false common sense beliefs is not.

Wilkins and Griffiths, however, do not go as far as claiming that common sense beliefs match reality. They argue that common sense beliefs can be accepted and acted upon but they are not as tolerant for common sense concepts. They elaborate:

Our commonsense concepts are themselves an evolutionary inheritance, and we know that they differ systematically from those of other animals. So it is plausible that if our evolution had followed a different course, we would have a different conceptual scheme. It is possible to see in this observation grounds for another kind of evolutionary skepticism. (...) [T] he commonsense way in which humans see the world has no more or less ontological authority than the ways in which other animals see the world. ${ }^{32}$

\footnotetext{
28 Wilkins and Griffiths (2013: 134).

29 The use of the term is an allusion to the battle at the Milvian bridge in 312 AD. Here Constantine beat his opponent Maxentius after having received a vision of the Christian God. According to the legend, Constantine won the battle because Christianity (or Christian beliefs) was true.

30 Wilkins and Griffiths (2013: 135).

31 Wilkins and Griffiths (2013: 155).

32 Wilkins and Griffiths (2013: 138).
} 
They refer to the physicist Arthur Eddington who contrasts the common sense belief that tables are solid objects with the scientific belief that tables are areas of mostly empty space of which the best that can be said is that the probability of his elbow sinking through it was small enough to be neglected for the purpose of writing his lecture (Eddington 1930). ${ }^{33}$ Wilkins and Griffiths note that an obvious rejoinder is that a belief in solid tables is a mere illusion and that, in fact, there are no solid tables. Their response is ambiguous, as they write:

But there is no reason to abandon the world of commonsense, as long as we are prepared to accept that we are not the only animal whose evolved perceptual and conceptual schemes can stand alongside the measurement and conceptual schemes of science, and be explained by it. There really are red things and green things, but there are also things which have ultra-violet colours that we cannot detect but other animals can. There are many ways of classifying the world which are not purely arbitrary and (...) the fact that these classifications are constrained by reality explains why they have some degree of pragmatic utility. ${ }^{34}$

In this response Wilkins and Griffiths seem to move from a claim that common sense beliefs are true to a claim that common sense beliefs are not purely arbitrary and constrained by reality. They add that our cognitive faculties evolved because they track truth in the human 'Umwelt'. As to scientific beliefs they claim its status does not depend on the reliability of the cognitive mechanisms that produce them. They write:

The reasons we have to think that our scientific conclusions are correct and that the methods we use to reach them are reliable are simply the data and arguments which scientists give for their conclusions, and for their methodological innovations. ${ }^{35}$

Wilkins' and Griffiths' argument for a Milvian bridge for common sense boils down to a claim that common sense beliefs can be considered not purely arbitrary and constrained by reality because of the pragmatic success they yield. According to Wilkins and Griffiths, no Milvian bridge is available for the mechanisms that give rise to supernatural belief. They write: "No Milvian bridge is available for religious beliefs, because none of the leading accounts of the evolution of religious belief makes any reference to the truth or falsity of those beliefs when explaining their effects on reproductive fitness". 36 The theories they refer to are the Costly Signaling Theory, Hyperactive Agency Detection and the Big Gods Theory. Since these theories show that supernatural beliefs can be produced without it being true

\footnotetext{
33 Eddington (1930) Quoted by Wilkins and Griffiths (2013: 138).

34 Wilkins and Griffiths (2013: 138 emphasis added).

35 Wilkins and Griffiths (2013: 138).

36 Wilkins and Griffiths (2013: 140) bearing in mind their own line of reasoning, their claim is best rephrased as "No Milvian bridge is available for supernatural beliefs, because none of the leading accounts of the evolution of supernatural belief makes any reference to them being constrained by reality when explaining their effects on reproductive fitness.'
} 
(because they are adaptations or by-products). They therefore show that supernatural cognition is not driven by truth in the same way sense cognition is.

Wilkins and Griffiths entertain the possibility of religious non-cognitivism where supernatural beliefs need not be about something but are mere expressions or ways of life. They conclude, however: "The truth of religious beliefs does seem to be a matter of tracking some external state of affairs, so that the question of whether evolution is an off-track process with respect to religious beliefs cannot be sidestepped. But the leading evolutionary explanations of these beliefs all suggest that they are produced by cognitive adaptations which do not track supernatural truths." 37 They do allow for a possibility how supernatural beliefs can be saved when they add that supernatural belief might be supported by other reasons like natural theology. ${ }^{38}$

Against their argument, I argue that Wilkins' and Griffiths' claim that supernatural beliefs do not yield pragmatic success and hence no Milvian Bridge is available for the mechanism that produces them is problematic. I argue that a case for pragmatic success of supernatural belief can be made. The pragmatic success of supernatural belief lies in the spiritual fruits it delivers. Supernatural beliefs can lead to greater spiritual fulfillment and a life of increased sanctity. To make a case for pragmatic success of supernatural beliefs, I draw on an argument made by William Alston who argued that supernatural beliefs allow for a test of sanctity. Alston made his claim as part of a broader defense of the rationality of religious experiences. His main claim is that religious experiences ${ }^{39}$ resemble sense perception in important regards and should therefore enjoy the same (or a similar) status. He notes that, at first glance, sense perception seems different because it allows for a test. Sense perception provides a 'map' of the physical and social environment and enables us to adjust our behavior accordingly and enables us to anticipate events. The 'map' allows us to test the outputs of sense perceptions and corrects them where they go wrong. Religious experiences cannot be tested by a 'map' of the physical and social environment. However, Alston claims they can be tested by a 'map' of the divine environment. The divine environment allows for a test of sanctification. When the outputs of religious experiences lead to a life of greater sanctity, they can pass the test. ${ }^{40}$ In this way, Alston shows that supernatural beliefs can make a claim to pragmatic success. Their success can consist of a life of greater sanctity. Greater sanctity can help people flourish. If supernatural beliefs were to lead to a life of lesser sanctity or more evil, people would function less well. In this case, one could claim that their (false) supernatural beliefs are frustrated by reality as well.

I have thus far claimed that the outputs of the mechanism responsible for supernatural belief can make the claim to pragmatic success Wilkins and Griffiths demand. My claim is, however, not yet sufficient. The debunker can still drive a wedge between the pragmatic success of sense perception and that of supernatural belief. They can claim that the pragmatic success of sense perception is much

\footnotetext{
37 Wilkins and Griffiths (2013: 141).

38 Wilkins and Griffiths (2013: 141).

39 Alston (1991) uses the term 'mystical perceptions'.

40 Alston (1991: 250-254).
} 
greater. Sense perception allows for scientific beliefs with a lot more impressive pragmatic success than supernatural beliefs. The success of scientific beliefs ranges from space rockets to cures for diseases. Its impressive success makes it very unlikely that beliefs resulting from sense perception are not aimed at truth. By comparison the success of supernatural belief appears meager.

This route is, however, not open for Wilkins and Griffiths. They appear to deny that scientific beliefs depend on human cognitive mechanisms by claiming they rely on the data and arguments scientists give. ${ }^{41}$ When assessing the pragmatic success of supernatural beliefs, the comparison should be limited to common sense beliefs.

The difference can be framed in another way that avoids reference to scientific beliefs. The debunker could claim that a world where humans lack accurate sense perception will be a very different world. People will be unable to navigate their environments and there will not be technological innovations. A world without mechanisms for supernatural belief would be far less different. Maybe people then would lead a life of greater sanctity and subjectively feel closer to God than without such mechanisms. However, the difference would clearly be less noticeable than the absence of accurate sense perception. It is thus far less clear what difference or what use supernatural beliefs make. In response, I don't see why supernatural belief should have the same degree of pragmatic success as sense perception does. It suffices that supernatural beliefs yield considerable pragmatic success. Wilkins and Griffiths deny that supernatural belief has any success at all. Alston shows that this is not the case. Furthermore, the difference supernatural belief makes should not be underestimated. Christianity clearly had a profound influence on western societies. Hinduism and Buddhism shaped the Indian subcontinent and spiritist beliefs influenced large parts of the world. While the difference supernatural belief make might not be as great as the difference of beliefs resulting from sense perception, its impact is surely big.

Additional evidence for my claim to pragmatic success for supernatural beliefs is that some supernatural beliefs can fail. In the case of perceptual beliefs, some will be discarded because they do not live up to the test of the environment. Someone who forms the belief that walls are penetrable will be kept in check when she hits her first wall. The belief can be said to lack pragmatic success because it resulted in failure to navigate the environment. In the case of supernatural belief, some beliefs will also be discarded for lack of pragmatic success as well. Examples are beliefs in premodern fertility cults. After the rise of city-states they lost their ground because they were unable to make sense of people's needs. They thus failed to cope with the (new) environment.

Wilkins and Griffiths suggest a different way to argue that the mechanism behind supernatural belief is unconstrained by reality. ${ }^{42}$ Wilkins and Griffiths discuss how

\footnotetext{
${ }^{41}$ Rik Peels argues that science does depend to a large extent on common sense. In this view scientific beliefs are partly formed by the same cognitive mechanisms that produce common sense beliefs (Peels 2017). Since Wilkins and Griffiths deny this point and I lack the time and space to assess it, I will not discuss this point any further.

42 I leave out 'completely arbitrary' because no belief-forming mechanism is completely arbitrary. All mechanisms are constrained in some way. What matters for Wilkins and Griffiths' argument is whether they are constrained by reality or not.
} 
another belief-forming mechanism can make a claim to a Milvian bridge, namely common sense, and argue that the mechanism behind supernatural belief does not resemble it sufficiently. Apart from issues of vagueness, this argument is problematic because the comparison is limited. If a mechanism does not resemble formation of common sense beliefs, it does not follow that the process is unconstrained by reality. A better way to rank the mechanism for supernatural beliefs under unreliable processes is by comparing it to a belief-forming mechanism we know is unconstrained by reality. I will do so by making a comparison to the self-serving bias.

The self-serving bias is a clear example of a belief-forming mechanism that is (largely) unconstrained by reality. Keith Campbell and Constantine Sedikides define the self-serving bias as: "[A tendency for] taking credit for personal success but blaming external factors for personal failure". ${ }^{43}$ The bias thus makes people prone to believe that they deserve all praise for personal successes and do not deserve blame for personal failures. ${ }^{44}$ Campbell and Sedikides review evidence for the claim that counterevidence to personal merit and external blame is very easily discarded or rationalized. Especially in situations of perceived threat people's beliefs persist. ${ }^{45}$ Campbell and Sedikides thus provide clear evidence that the beliefs resulting from the self-serving bias are unconstrained by reality. Sander Koole notes that biases like the self-serving bias often serve to ward off negative emotions like anxiety. He also claims they serve the larger goal of emotion-regulation. These are defensive responses, which protect the individual from changing her outlook. ${ }^{46}$ From Campbell and Sedikides and Koole's discussion of the self-serving bias I derive the following characteristics of belief-forming mechanisms that are unconstrained by reality. They:

(i) Are insensitive to counterevidence

(ii) Ward of negative emotions

(iii) Have a rather fixed outcome

The first characteristic is to be expected for belief-forming mechanisms that are unconstrained by reality. If a mechanism is unconstrained by reality its operations will not be altered by evidence from reality. Its operations will also be insensitive to evidence that is not from reality, for example false or confabulated evidence, but this is irrelevant for our purposes. The mechanism responsible for supernatural beliefs does not meet the first criterion. Of the three theories Wilkins and Griffiths refer to, HADD unambiguously has an important role for evidence in the production of supernatural beliefs. We noted how Barrett argues that supernatural beliefs can be

\footnotetext{
43 Campbell and Sedikides (1999: 23).

44 For a number of reasons it cannot be claimed that the bias is solely responsible for the production of beliefs. Other factors like the social environment and the proximate reasons that give rise to the belief also must be taken into account. In any case, the self-serving bias is still a major contributor to belief in personal merit and external blame and other factors are probably less important. This suffices for our purposes here.

45 Campbell and Sedikides (1999).

46 Koole (2009).
} 
formed after experiences of things like wispy forms. There are also independent reasons to think that supernatural beliefs and how they are formed are sensitive to evidence. People sometimes report life-changing religious experiences that gave their lives a radically new direction. There are also ample examples of people coming to belief in supernatural beings. Therefore, supernatural beliefs and how they are formed do not appear to share the first characteristic.

The second characteristic stems from the observation that biases are defense mechanisms. They defend people against perceived threats and allow them to function better. In a way biases like the self-serving bias lead people to believe that states of affairs are better than they are in reality. While evidence against personal merit or for external merit can lead to feelings of failure or anguish, the self-serving bias makes sure that feelings of self-worth survive. In short, it makes people feel better. The mechanism behind supernatural belief does not unambiguously make people feel better. It might put demands on people that they perceive as burdensome. Therefore, supernatural beliefs and how they are formed do not appear to share the second characteristic either.

The third characteristic is that mechanisms that are unconstrained by reality produce rather similar beliefs that are not subject to much change. The self-serving bias only has belief in personal merit and external blame as output. Furthermore, the beliefs are not subject to much change. This fits well with mechanisms unconstrained by reality because the beliefs are not shaped by reality. Clearly supernatural beliefs can differ to some extent depending on the experience an individual has had. Supernatural beliefs also often change over time. Alston notes that sometimes an increase in sanctity can be observed in supernatural beliefs. Therefore, supernatural beliefs do not seem to share the third characteristic either.

I conclude that both evolutionary arguments are unconvincing. Goodnick's argument suffers from obvious flaws. Wilkins' and Griffith's argument, though more intricate, also does not hold water upon further scrutiny.

\section{False god-beliefs unreliability arguments}

Matthew Braddock proposes a different unreliability argument. He claims that the mechanism responsible for supernatural belief is unreliable because it produces many false god-beliefs. His argument is the following:

[9] Polytheistic beliefs and finite-god beliefs are false god beliefs.

[10] CSR mechanisms have disposed us humans to such god beliefs across ordinary environments and throughout human history.

[11] So, CSR mechanisms have disposed us humans to a large percentage of false god-beliefs across ordinary environments and throughout human history. [From [9] and [10]]

[12] Given [11], we should suspend judgment about the reliability of CSR mechanisms in ordinary environments with respect to the class of god beliefs, unless we have independent evidence favoring reliability. 
[13] We have no independent evidence favoring the reliability of CSR mechanisms in ordinary environments with respect to the class of god beliefs.

[14] So, we should suspend judgment about the reliability of CSR

mechanisms in ordinary environments with respect to the class of god beliefs. [From [12] and [13]] $]^{47}$

Braddock's conclusion [14] is slightly different than the conclusions from the arguments I discussed above. He merely concludes that we should be agnostic about the reliability of CSR-mechanisms; the arguments above concluded that the mechanisms are shown to be unreliable. It is not immediately clear whether agnosticism about the unreliability of a belief-forming mechanism implies a serious epistemic deficit of the beliefs it produces. One could argue that the burden of proof is on the one who argues against the reliability of a mechanism. Those who have a stricter take on the matter might argue that the burden of proof is on the defender. Braddock's expanded argument (see below) shows that he belongs to the stricter camp. I will not take a stance on this matter and go along with Braddock and the stricter camp. In this regard, Braddock's conclusion comes very close to the conclusions of the evolutionary arguments above.

His first premise makes clear that Braddock takes false god-beliefs to be nonmonotheistic god-beliefs. According to monotheism, there is only one God. If monotheism is true, then polytheistic beliefs must be false. He adds that many nontheists will also accept the premise and even many polytheists if the premise was changed slightly to 'the vast majority of polytheistic and finite god beliefs are false'. 48

With premise [10], Braddock notes that the mechanisms laid bare by CSRtheories dispose humans to having polytheistic beliefs and finite god-beliefs. Braddock argues for this point at length. In his discussion he is, however, less firm. He writes: "[V]arious lines of converging evidence suggest that CSR mechanisms have disposed us humans to polytheistic and finite (...) god beliefs throughout the human past." 49 His phrase "throughout the human past' reveals that much of the alleged false outputs of CSR-mechanisms are to be situated a long time ago in human history. Braddock discusses how polytheistic and finite god-beliefs were prevalent among ancestral humans. He then refers to a version of the Big Gods Theory to argue that monotheistic beliefs are a recent innovation. ${ }^{50}$ Braddock thereby suggests that an assessment of (un)reliability should look at the whole evolutionary history of a mechanism. It is far from clear that such a requirement is needed. If we would apply this logic to our perceptual faculties, we would note that they too produced many false beliefs. For a good part of human history, people formed the belief that the earth was flat and that the sun revolved around the earth based on perception. If we follow Braddock's requirement, we should conclude that

\footnotetext{
47 Braddock (2016: 270).

48 Braddock (2016: 272).

49 Braddock (2016: 272 emphasis added).

50 Braddock (2016).
} 
perception produces a lot more false beliefs and is thus a lot more unreliable. It makes much more sense to assess perception by looking at how many false beliefs it produces in the present. If we assess CSR-mechanisms in the same way, we note that nowadays they produce a lot more monotheistic beliefs and the case for [10] is less strong. ${ }^{51}$

Braddock also refers to other CSR-theories than the Big Gods Theory to argue for [10]. He refers to Justin Barrett and Paul Bloom who both state that polytheism is more natural or intuitive than monotheism. ${ }^{52}$ Premise [10] is probably correct if Barrett's or Bloom's theory is true. However, some CSR-theories suggest a preference for monotheistic beliefs. The Moral Dyad predicts belief in an ultimate moral agent; the Existential Theory of Mind predicts belief in an ultimate meaninggiver; and the Big Gods Theory predicts belief in big gods. Furthermore, Barrett also claims that the human theory of mind produces intuitive beliefs in superproperties like omniscience that fit much better with monotheistic beliefs. ${ }^{53}$ Although the truth of premise [10] is not established, there are reasons to think that some CSR-mechanisms produce more polytheistic and finite god beliefs. For this reason, I will grant [10] in the rest of this section.

I also will not dispute premise [13], or Braddock's conclusions [12] and [14]. I merely note at this point that Braddock's argument is not an argument for the conclusion that supernatural belief is unreliably formed. It merely concludes that the mechanisms laid bare by CSR-theories are unreliable. The unreliability of CSRmechanisms might be overcome by other forces that shape supernatural beliefs. Braddock acknowledges this point and expands his argument with the following:

[15] CSR mechanisms operating in ordinary environments are significant contributors to the god beliefs of past and present humans. [CSR's empirical thesis]

[16] If we should suspend judgment about the reliability of significant contributors to a belief-forming process $\mathrm{P}$ with respect to a class of beliefs $\mathrm{C}$, and we have no good reason to think other significant contributors would confer reliability upon $\mathrm{P}$ with respect to $\mathrm{C}$, then we should suspend judgment about the reliability of $\mathrm{P}$ with respect to $\mathrm{C}$.

[17] We have no good reason to think other significant contributors to our belief-forming processes would confer reliability upon them with respect to the class of god beliefs.

\footnotetext{
51 A recent study claimed that over $50 \%$ of the world population were either Christian or Muslim (Hackett and Grim 2012). To this Jews, a subset of Hindus, a subset of Buddhists and some adherents of folk religions can be added. Nowadays, more people are monotheistic than polytheistic.

52 Braddock (2016) Barrett writes: "In a certain respect, believing in numerous superhuman agents appears to be the most natural type of belief system." (Barrett 2012a: 141-42) quoted by Braddock (2016: 274 emphasis added)

Bloom writes: "[T]here is no evidence that a belief in a single God...is unlearned. As best we know, such a belief is not a universal, and it does not emerge without social contact. (...) but these properties apply better to supernatural belief more generally, not to belief in God" (Bloom 2009: 127) quoted by Braddock (2016: 274).

53 Barrett (2004: 77).
} 
[18] So, we should suspend judgment about the reliability of our beliefforming processes with respect to the class of god beliefs. [From [14] to [17]]

[19] If we should suspend judgment about the reliability of a belief-forming process $\mathrm{P}$ with respect to a class of beliefs $\mathrm{C}$, then we are not justified in holding a particular belief $\mathrm{B}$ that is both produced by $\mathrm{P}$ and falls into class $\mathrm{C}$, absent independent evidence for B.

[20] So, we are not justified in holding our god beliefs, absent independent evidence for them. [From [18 and [19]] ${ }^{54}$

I will contend [17] and argue that there is reason to think that other significant contributors to supernatural belief can confer reliability. I thus grant for the sake of the argument that the mechanisms can be judged unreliable (although I claimed that the case for [10] is not as strong as Braddock argues), but I hold that such unreliability need not affect all supernatural beliefs. A number of CSR-theorists acknowledge that the mechanisms they discuss do not work in isolation but always work in a cultural context. Though they do not give details, they leave it open that cultural input can give further direction to supernatural belief. Will Gervais and Joseph Henrich, for example, note that most CSR mechanisms cannot explain why people used to believe in ancient gods like Zeus but do not anymore. To explain this, culture must be taken into account. ${ }^{55}$

A similar point was also raised by Aku Visala and David Leech. They write:

[I]t is not, in fact, the case that the standard model [the cognitive optimum, HADD, EtoM]gives us a complete account of the existence and persistence of particular and content-specific theistic beliefs. [...] [T] here are far more mechanisms involved in particular belief formation than are specified by the standard model. Even if it turns out that the cognitive mechanisms that the standard model posits are unreliable, the irrationality of theism does not follow. In other words, if the standard model catches only some causal pathways through which the theist's beliefs come about, then it is perfectly possible that the other pathways are rational. This is enough, we claim, to dismantle the unreliability arguments as they stand now. ${ }^{56}$

Visala and Leech's response is not exactly the same as mine. ${ }^{57}$ They argue that the mechanisms laid bare by CSR are only one pathway among others that lead to supernatural beliefs. The other pathways remain unaffected by the alleged

\footnotetext{
54 Braddock (2016: 271).

55 Gervais and Henrich (2010).

56 Leech and Visala (2011: 311).

57 Braddock responds to Leech and Visala's claim by limiting the scope of his argument. He argues that people who don't have access to other pathways still face a problem. He writes: "[T]he dialectical context of the paper's question is this: if such arguments are not available (because the believer is not aware of them, or because there are no such convincing arguments), does the believer possess a defeater for her non-inferential belief?" He answers this question affirmatively (Braddock 2016: 277). By limiting the scope of his argument in this way, Braddock seems to acknowledge that Leech and Visala's response can help supernatural beliefs evade the charge of unreliability.
} 
unreliability of CSR-mechanisms. In my response, I argue that the unreliability of CSR-mechanisms can be overcome by other factors.

Braddock did not claim that the mechanisms laid bare by CSR-theories are wholly unreliable. From a monotheist perspective, they occasionally produce true god beliefs, namely monotheistic beliefs. Cultural input, like education, study or growing up in a religious community, can work on the initial outputs of the mechanism and redirect them to jointly produce monotheistic beliefs.

This all goes to show that the mechanisms laid bare by cognitive science of religion are not themselves responsible for the supernatural beliefs people hold. Their initial outputs can lead to many false god-beliefs but this deficiency can be overcome. Two factors that can bear on religious belief are upbringing and cultural context. Someone who grows up in a monotheistic household and lives in a cultural setting where most people are monotheists is more likely to become monotheistic herself. Influence of upbringing and cultural context can come in two forms. A child can be instructed with words, for example by religious education. A child can also be influenced by seeing outward religious behavior. Research by Jonathan Lanman and Michael Buhrmester showed that exposure to CRED's (credibility enhancing displays) predicts theism, certainty of God's existence and religiosity. ${ }^{58}$ CRED's are outward behaviors that clearly indicate that someone is strongly committed to a belief. ${ }^{59}$ Examples are engaging in rituals, praying before each meal or wearing religious symbols. Outward behavior by people who are monotheistic can make people more likely to become monotheistic themselves.

I thus conclude that while Braddock makes a good case for the unreliability of CSR-mechanisms, he did not make a good case that this affects supernatural beliefs. He did not take into account other contributors to supernatural beliefs that could overcome the unreliability of CSR-mechanisms.

\section{Incompatible god-beliefs unreliability arguments}

Another reason why the mechanism responsible for supernatural belief might be judged unreliable is because it produces incompatible beliefs. CSR mechanisms appear to produce both the belief in monotheism and infinite gods and the belief in polytheism and finite gods. Since monotheism is the belief that there is only one god, it is logically incompatible with polytheism, the thesis that there are multiple gods. A belief that $\operatorname{god}(\mathrm{s})$ is (are) finite is also incompatible with a belief that god(s) are infinite. A mechanism that produces incompatible beliefs will produce many false beliefs and can thus be judged unreliable. To my knowledge this argument has not been defended at length. Matthew Braddock mentions it but deems it less promising than his own debunking argument. He writes:

Why does the argument need to rely on the falsity of polytheistic and finite god beliefs when the diversity of god beliefs already establishes many

\footnotetext{
58 Lanman and Buhrmester (2017).

59 Henrich (2009).
} 
incompatible (and thus false) god beliefs?" The main reason for relying on [9] [Braddock's premise that CSR-mechanisms produce god-beliefs] is that doing so enhances the strength of the argument's case against reliability. The incompatibility established by religious diversity only implies that at least some god beliefs are false. That is not enough to doubt reliability. Premise [9], on the other hand, helps generate the requisite level of doubt. To appreciate this, suppose that there are in fact many finite gods. When we add to this the empirical premise that most god beliefs have been of the polytheistic and finite sort, it is no longer clear that our natural god belief-forming mechanisms are off track. ${ }^{60}$

The argument goes as follows:

(22) The scientific evidence shows that the mechanisms for supernatural beliefs produce many incompatible beliefs.

(23) Mechanisms that produce many incompatible beliefs are unreliable.

(24) Therefore, the scientific evidence shows that the mechanisms for supernatural beliefs are unreliable.

Despite the shortcomings to which Braddock hints, arguing that the mechanism is unreliable because it produces incompatible beliefs has the benefit that it need not take a monotheistic or naturalistic perspective as did the previous argument.

This argument rests on the claim that mechanisms that produce incompatible beliefs are unreliable. A mechanism that produces incompatible beliefs will produce false beliefs. This follows from the logical law of non-contradiction. Apart from a few voices of opposition, ${ }^{61}$ the law of contradiction is widely accepted. However, claiming that the mechanism produces some false beliefs is not sufficient to judge it unreliable. An unreliability judgment requires that the mechanism is error-prone, or produces many false beliefs. The mechanisms Braddock refers to do indeed appear to produce many polytheistic, finite god-beliefs and also many monotheistic, infinite god-beliefs. So on both monotheism and polytheism, they produce many false beliefs.

Still, we can claim that the mechanism is not wholly unreliable and needs cultivation in order to arrive at true beliefs. There is yet another response possible, though, which denies that the mechanism produces many incompatible god-beliefs. I will claim that although the mechanisms can be claimed to produce supernatural beliefs, a belief that a supernatural being is a god requires more. In my response I do not accept Braddock's claim that the mechanisms responsible for supernatural belief produce many finite and polytheistic god-beliefs. I do accept that the mechanisms produce beliefs in a multitude of finite supernatural beings but these beings need not be considered gods. These supernatural beings can be considered gods and thus lead to a polytheistic worldview. However, they can just as well be considered intermediary supernatural beings and be fitted in with a monotheistic worldview. In this framework, the incompatibility between polytheistic belief and monotheistic

60 (Braddock 2016: 272).

61 See for example Priest and Berto (2013). 
belief is due to how the beliefs produced by the mechanisms are regarded or interpreted, not because of how the mechanisms operate. Therefore, incompatible god-beliefs (or rather supernatural beliefs) cannot be attributed to the mechanisms.

The beliefs produced by CSR-mechanisms are rather vague. They produce beliefs that some supernatural being exists or that some supernatural being is like this or that. For example, on the Existential Theory of Mind the EToM produces the belief that some supernatural being is communicating something through a meaningful event. It does not produce the belief that this supernatural being is the one and only god or that the being is (in)finite. The moral dyad produces belief that some supernatural being is responsible for a morally significant event. It also does not produce the belief that there is only one god that causes these events or that that being is (in)finite.

The vagueness of the beliefs that CSR-mechanisms yield is attested by CSRtheorists. ${ }^{62}$ They note that none of the mechanisms produce concrete beliefs that the Christian God exists or that Vishnu descended in the form of a tortoise. Concrete beliefs require cultural input and interpretation against a cultural background. Justin Barrett notes that cognitive theories of supernatural belief focus on cross-culturally recurrent ideas (and practices). Focusing on Christianity, he claims that many components of it consist of only small elaborations on the cross-culturally recurrent ideas. On the other hand, some Christian ideas deviate. Examples are the idea of God as absolutely sovereign or God as all-knowing. ${ }^{63}$ Barrett thereby points to a gap between what cognitive mechanisms yield and the more elaborate, concrete beliefs people hold. In line with this idea, I argue that what cognitive mechanisms yield does not suffice to make a distinction between 'supernatural being' and 'god'. A mechanism can produce beliefs that some supernatural being exists and also beliefs about that being's nature. Classifying that being as a 'god' requires more. ${ }^{64}$ In some traditions, a multitude of supernatural beings will be considered gods and a polytheistic worldview will emerge. This was the case in ancient Rome and in some strands of contemporary Hinduism. In other traditions, only one supernatural being will be considered a god. Other supernatural beings will have an intermediary status; they are not considered human or gods. This is the case in Christianity where many supernatural beings are considered angels or demons and in Islam where many are considered jinns.

My response to incompatible unreliability arguments differs from my response against false god-beliefs arguments. In the latter, I granted the unreliability of the CSR-mechanisms but argued that they can be corrected by other input (like culture or upbringing). In the former I did not grant the unreliability CSR-mechanisms. I

\footnotetext{
62 I noted that a number of CSR-theorists acknowledge the gap between culturally specific supernatural beliefs and vaguer beliefs yielded by CSR-mechanisms in my review of the book 'Religion Explained? The Cognitive Science of Religion After Twenty-Five Years, edited by Luther H. Martin and Donald Wiebe.' (Van Eyghen 2018).

63 Barrett (2012b).

64 Distinguishing gods from supernatural beings that are not gods is difficult and religious traditions appear to have different criteria. In general, gods appear to enjoy a higher standing than other supernatural beings. They are often considered as more powerful or more worthy of praise. For the purposes of this paper, it suffices that there is a distinction between gods and other supernatural beings.
} 
deny that the production of both monotheistic and polytheistic beliefs can be attributed to the mechanisms. Here the root of the incompatibility lies in other factors like culture or upbringing. This raises an interesting point. Whereas factors like culture or upbringing can correct false god-beliefs, they can also lead people astray. The factors can thus be both a source of epistemic good and of epistemic bad. I certainly cannot shed light on when these factors are a benevolent influence and when they are malevolent in this paper and I doubt whether it can be done at all. I merely note that in both cases extra input on top of the CSR-mechanisms can defeat unreliability arguments and this suffices for now.

\section{Offtrack unreliability arguments}

A final unreliability argument concludes to unreliability from the internal logic of some CSR-theories. Robert Nola proposes an unreliability argument in which the mechanisms that produce supernatural beliefs are deemed unreliable because those mechanisms can independently be judged error-prone. The argument can be stated as follows:

(25) The scientific evidence shows that the mechanisms for supernatural belief are offtrack.

(26) Mechanisms that are offtrack are unreliable.

(27) Therefore, the scientific evidence shows that the mechanisms for supernatural belief are unreliable.

Apart from raising similar worries about the reliability of evolved belief-forming mechanisms we discussed earlier, Nola offers a different unreliability argument. He writes: "[V]arious mechanisms causing religious belief are 'offtrack", ${ }^{65}$ Nola does not define 'being offtrack'. He seems to argue that various mechanisms for supernatural belief are not appropriately tuned for tracking truth. A first offtrack mechanism Nola discusses is Sigmund Freud's theory of wish fulfillment. ${ }^{66}$ I will leave this discussion aside because Freud's theory is now widely discarded. ${ }^{67}$ Another mechanism Nola discusses is the Hyperactive Agency Detection Device (HADD) and the Cognitive Optimum. Nola stresses HADD's proneness to overdetect and thus to produce 'false positives'. He also argues that HADD is offtrack because humans no longer live in the domain for which HADD evolved. The cognitive environment in which humans live now is very different to the one of our ancestors for whom HADD evolved. He also stresses the same shortcoming of human folk ontology as it features in Boyer's Cognitive Optimum.

I will argue against premise (26). I argue that although some mechanisms for supernatural belief are somewhat offtrack, they are not unreliable. Against Nola's first claim I argue that there is no non-question begging way to rank all detected

\footnotetext{
65 Nola (2013: 169).

66 cf. Freud (1961).

67 See for example Whittaker (1978).
} 
supernatural agents under 'false positives'. On Barrett's theory, HADD indeed produces many false positives. However, not all falsely detected agents are supernatural; a subject will also often falsely detect non-existing predators or other humans. Humans will also occasionally identify inanimate objects as agents. ${ }^{68}$ When laying out his theory, Barrett discusses how HADD can give rise to belief in ghosts or spirits. He claims that they can result from identifying ambiguous things, such as wispy forms, as intentional agents. He writes: "Whether the sighting is an illusion or not, if the right information is fed to these mental tools, the outcome is a nonreflective belief in a ghost or spirit. Without sufficient reflective defenses, this nonreflective belief will become a reflective one." 69 The quote shows that Barrett leaves open the possibility that not all sightings that lead to belief in ghosts or spirits are illusions. Barrett also discusses a second way HADD can produce supernatural beliefs. HADD can register evidence as resulting from a known agent. A storm cloud can be identified as an act of God. In cases like these, HADD does not so much produce a new supernatural belief but rather encourages belief in a known supernatural agent. ${ }^{70}$ In any case, it is clear that Barrett does not rank all detected supernatural agents under false positives.

HADD thus does not allow the conclusion that all detected supernatural agents are false positives. While some beliefs in supernatural beings will result from hyperactivity, this also holds for non-supernatural agents. The argument thus targets supernatural and non-supernatural agents equally. Since claiming that some beliefs about non-supernatural agents result from hyperactivity does not disqualify all of them, the same can be claimed for belief in supernatural agents.

With this in mind, Nola could still maintain that HADD is offtrack. Even if not all detected supernatural agents can be ranked under false positives, the mechanism still leads to beliefs in agents when none are present. HADD can thus be argued to be offtrack in the detection of supernatural agents and natural agents. If he argues for that, Nola compromises the epistemic status of our beliefs in human and animal agents too. In a paper with Ian Church, Justin Barrett makes a similar claim. He claims that any claim that CSR-mechanisms are offtrack has implications that range far wider than supernatural beliefs. They write: "Religious beliefs are not the only beliefs these faculties [CSR-mechanisms HvE] form, however. If they are unreliable when forming metaphysical beliefs about the existence of gods, souls, and the afterlife, are they reliable to deliver true beliefs regarding the features and causal properties of the natural world, the social world, human minds, and moral realities?"71 Applied to HADD, especially belief in human minds seem to be compromised if HADD is judged offtrack. In response to this challenge, Nola could grant that HADD is also offtrack when producing belief in natural agents but add that there are additional reasons for holding beliefs about natural agents. He could

\footnotetext{
${ }^{68}$ Barrett refers to the famous Heider Simmel study (Heider and Simmel 1944). In this study people were shown a short video of two geometric figures moving and were asked to describe what they saw. Many gave descriptions using mental states like 'the figure liked each other' or 'the figures fell in love'.

69 Barrett (2004: 33).

70 Barrett (2004).

71 Barrett and Church (2013: 16-17).
} 
also respond that when an agent is repeatedly detected, HADD is more reliable. If he responds in this way, Nola can no longer use HADD's being offtrack to argue for a serious epistemic deficiency of supernatural beliefs. I noted when criticizing Braddock's argument that there can be additional reasons for holding supernatural beliefs. HADD can also repeatedly detect supernatural agents.

Nola argues that other theories than HADD can be plugged in to argue for his conclusion. Defenders of other CSR-theories indeed also suggest that the mechanism producing supernatural beliefs is off-track. Kurt Gray and Daniel Wegner suggest that people erroneously attribute disasters and the like to an ultimate moral agent. Jesse Bering suggests that people mistakenly see meaningful events as communications of an ultimate meaning-giver. Both theories thus suggest that supernatural beliefs result from cognitive mistakes or false positives. Both claims, however, seem to presuppose that there are no ultimate moral agents or ultimate meaning-givers. Gray and Wegner do not entertain the possibility that there is an actual ultimate moral agent that is detected by the Moral Dyad. Bering also does not argue against the possibility of an actual ultimate meaning-giver. This strongly suggests that all authors shared the presupposition that no supernatural being can be involved in the production of supernatural beliefs. With this presupposition it is no surprise that the authors see supernatural beliefs as resulting from mistakes. Arguing for unreliability with theories that share such a presupposition makes the argument question begging.

Nola's other claim, i.e. that the HADD-mechanism and human folk ontology evolved to solve problems for our distant human ancestors, might imply being offtrack but does not imply unreliability. His claim also faces a backlash against many other belief-forming mechanisms. One cognitive mechanism that is compromised by Nola's argument is the theory of mind. According to Daniel Povinelli and Todd Preuss theory of mind might be the result of evolutionary changes in the prefrontal cortex. ${ }^{72}$ The prefrontal cortex evolved early in human history. Following Nola, a case can be made that our mechanism for understanding mental states is not well suited for our current environment and is therefore unreliable. We, however, do appear able to form many correct beliefs about other people's mental states. We often err and suffer from biases but this does not disqualify our whole ability to understand mental states. Its shortcomings can be rectified by other cognitive mechanisms or by reasoning processes. There is no reason to think that this is not also possible for HADD and folk ontology.

My responses to both of Nola's claims show that being offtrack does not amount to unreliability. Nola rightly claims that HADD and human folk ontology are somewhat offtrack and result in false positives. The errors are, however, not as grave as Nola argues.

\footnotetext{
72 Povinelli and Preuss.
} 


\section{Conclusion}

None of the arguments I surveyed in this paper make a successful case that supernatural beliefs are unreliably formed. One argument, namely Braddock's argument that CSR-mechanisms are unreliable because they produce many false god-beliefs, might be able to make the case that the mechanisms laid bare by CSRmechanisms are unreliable. I argued that this unreliability can be overcome.

Open Access This article is distributed under the terms of the Creative Commons Attribution 4.0 International License (http://creativecommons.org/licenses/by/4.0/), which permits unrestricted use, distribution, and reproduction in any medium, provided you give appropriate credit to the original author(s) and the source, provide a link to the Creative Commons license, and indicate if changes were made.

\section{References}

Alston, W. P. (1991). Perceiving god: The epistemology of religious experience. Ithaca, NY: Cornell University Press.

Barrett, J. L. (2004). Why would anyone believe in god?. Walnut Creek: Altamira Press.

Barrett, J. L. (2007). Is the spell really broken? Biopsychological explanations of religion and theistic belief. Theology and Science, 5, 57-72.

Barrett, J. L. (2012a). Born believers: The science of children's religious belief. New York: Free Press. Barrett, J. L. (2012b). Towards a cognitive science of Christianity. In J. B. Stump \& A. G. Padgett (Eds.), The Blackwell companion to science and Christianity. Oxford: Blackwell Publishing.

Barrett, J. L., \& Church, I. M. (2013). Should CSR give atheists epistemic assurance? On beer-goggles, BFFs, and skepticism regarding religious belief. The Monist, 96, 311-324.

Bering, J. (2002). The existential theory of mind. Review of General Psychology, 6, 3-24.

Bering, J., \& Johnson, D. (2005). "O Lord... You perceive my thoughts from Afar": Recursiveness and the evolution of supernatural agency. Journal of Cognition and Culture, 5, 118-143.

Bloom, P. (2009). Religious belief as an evolutionary accident. In M. Murray \& J. Schloss (Eds.), The believing primate. New York: Oxford University Press.

Boyer, P. (2002). Religion explained: The human instincts that fashion gods, spirits and ancestors. London: Vintage.

Braddock, M. (2016). Debunking arguments and the cognitive science of religion. Theology and Science, 14, 268-287.

Campbell, W. K., \& Sedikides, C. (1999). Self-threat magnifies the self-serving-bias: A meta-analytic integration. Review of General Psychology, 3, 23-43.

Clark, K. J. (2010). Explaining god away? In M. Y. Stewart (Ed.), Science and religion in dialogue. Hoboken: Blackwell Publishing.

Clark, K. J., \& Barrett, J. L. (2010). Reformed epistemology and the cognitive science of religion. Faith and Philosophy, 27, 174-189.

Clark, K. J., \& Rabinowitz, D. (2011). Knowledge and the objection to religious belief from cognitive science. European Journal for Philosophy of Religion, 3, 67-81.

Conee, E., \& Feldman, R. (1998). The generality problem for reliabilism. Philosophical Studies, 89, 1-29.

Eddington, A. S. (1930). The nature of the physical world. Cambridge: Cambridge University Press.

Freud, S. S. (1961). The future of an illusion; civilization and its discontents and other works. London: Hogarth Press.

Gervais, W., \& Henrich, J. (2010). The Zeus problem: Why representational content biases cannot explain faith in gods. Journal of Cognition and Culture, 10, 383-389.

Goodnick, L. (2016). A De Jure criticism of theism. Open Theology, 2, 23-33.

Hackett, C., \& Grim, B. J. (2012). The global religious landscape. A report on the size and distribution of the world's major religious groups as of 2010. The Pew Research Center. Accessed November 28, 2016. 
Heider, F., \& Simmel, M. (1944). An experimental study of apparent behavior. The American Journal of Psychology, 57, 243-259.

Henrich, J. (2009). The evolution of costly displays, cooperation and religion: Credibility enhancing displays and their implications for cultural evolution. Evolution and Human Behavior, 30, 244-260.

Johnson, D. P. (2015). God is watching you: How the fear of god makes us human. New York: Oxford University Press.

Jones, J. W. (2016). Can science explain religion? The cognitive science debate. Oxford: Oxford University Press.

Jong, J., \& Visala, A. (2014). Evolutionary debunking arguments against theism, reconsidered. International Journal for Philosophy of Religion, 76, 243-258.

Koole, S. L. (2009). The psychology of emotion regulation: An integrative review. Cognition and Emotion, 23, 4-41.

Lanman, J. A., \& Buhrmester, M. D. (2017). Religious actions speak louder than words: Exposure to credibility-enhancing displays predicts theism. Religion, Brain \& Behavior, 7, 3-16.

Leech, D., \& Visala, A. (2011). The cognitive science of religion: A modified theist response. Religious Studies, 47, 301-316.

Murray, M. J. (2008). Four arguments that the cognitive psychology of religion undermines the justification of religious belief. In J. Bulbulia, R. Sosis, E. Harris, R. Genet, C. Genet, \& K. Wyman (Eds.), The evolution of religion: Studies, theories, and critiques. Santa Margarita: Collins Foundation Press.

Nola, R. (2013). Do naturalistic explanations of religious beliefs debunk religion? In G. W. Dawes \& J. Maclaurin (Eds.), A new science of religion. New York, London: Routledge.

Oviedo, L. (2018). Explanatory limits in the cognitive science of religion: Theoretical matrix and evidence levels. In H. Van Eyghen, R. Peels, \& G. Van den Brink (Eds.), New developments in cognitive science of religion-The rationality of religious belief. Dordrecht: Springer.

Peels, R. (2017). The fundamental argument against scientism. In M. Boudry \& M. Pigliucci (Eds.), Science unlimited? The challenges of scientism. Chicago: Chicago University Press.

Plantinga, A. (2011). Where the conflict really lies: Science, Religion, and Naturalism. Oxford: Oxford University Press.

Priest, G., \& Berto, F. (2013). Dialetheism. In E. N. Zalta (Eds.), The Stanford encyclopedia of philosophy (summer 2013 edition).

Szocik, K. (2018). Adaptationist accounts can tell us more about religion than cognitive accounts can. In H. Van Eyghen, R. Peels, \& G. Van den Brink (Eds.), New developments in cognitive science of religion-The rationality of religious belief. Dordrecht: Springer.

Thurow, J. C. (2013). Does cognitive science show belief in god to be irrational? The epistemic consequences of the cognitive science of religion. International Journal for the Philosophy of Religion, 74, 77-98.

Van Eyghen, H. (2018). Book reviews. Religion explained? The cognitive science of religion after twenty-five years. Journal for the Cognitive Science of Religion, 4, 111-114.

Van Inwagen, P. (2009). Explaining belief in the supernatural. Some thoughts on Paul Bloom's 'religious belief as evolutionary accident'. In J. Schloss \& M. J. Murray (Eds.), The believing primate: Scientific, philosophical, and theological reflections on the origin of religion. New York: Oxford University Press.

Whittaker, J. H. (1978). Causes, reasons, and the genetic fallacy. Journal of the American Academy of Religion, XLVI, 351-368.

Wilkins, J. S., \& Griffiths, P. E. (2013). Evolutionary debunking arguments in three domains: Fact, value, and religion. In G. Dawes \& J. Maclaurin (Eds.), A new science of religion. London: Routledge. 